\title{
Proffle
}

\section{Dr. Manzar Ashtari, an Achiever Despite the Odds}

S everal years back I was asked to nominate a woman from the Muslim community for an award given annually by the Long Island Fund for Women and Girls (LIFWG) at its Women Achievers Against the Odds annual awards breakfast. This award recognizes women for their achievements despite difficult circumstances.

I immediately thought about Manzar Ashtari, $\mathrm{PhD}$, whom I had known as a colleague on Long Island. She breaks every possible stereotype regarding Muslim women. She came to the United States from Iran on a merit scholarship, learned English, and obtained a doctorate in nuclear engineering from Massachusetts Institute of Technology (MIT). she developed novel neuroimaging techniques, which help explain the behavior of autistic children and shed new insights into devastating diseases such as schizophrenia and Alzheimer's disease. Through these achievements, she is a recognized researcher and trailblazer in her field.

I was delighted to attend the LIFWG awards breakfast on November 9, 2005, where Dr. Ashtari in the presence of more than 800 attendees, received this coveted recognition and shared her jihad (struggle) with the attendees.

Dr. Ashtari is a full professor at the University of Pennsylvania Department of Radiology and the director of the Diffusion Tensor Image Analyses and Brain Morphometry Center in the Department of Radiology of the Children's Hospital of Philadelphia. She was previously the director of the Function Brain Laboratory at the Long Island Jewish-North Shore Health System and associate professor of radiology and psychiatry at Albert Einstein College of Medicine in New York, where for more than 22 years she led groundbreaking research on the brain and its complex illnesses via the advanced methods of magnetic resonance imaging (MRI).

After completing her bachelor of science at Tehran University in 1974, Dr. Ashtari placed first in

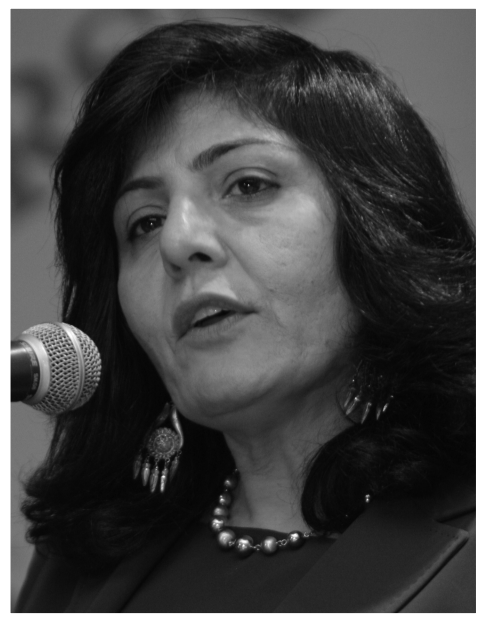

Manzar Ashtari, PhD two independent masters degree programs, the nuclear physics program at Tehran University and the nuclear engineering program at the Atomic Energy Organization of Iran (AEOI). This exceptional achievement changed the course of her future. she was selected among hundreds of students to be awarded a full scholarship to study nuclear engineering at MIT. In 1982, she received her PhD with a thesis on the treatment of glioblastoma brain tumors using a nuclear reactor's neutron beam. Fascinated by the application of the field of nuclear engineering in medicine, Dr. Ashtari subsequently received extensive training in the field of medical physics and has since been involved in the research of psychiatric illnesses such as schizophrenia, obsessive compulsive disorder (OCD), attention deficit hyperactivity disorder (ADHD), Alzheimer's disease, and, most recently, autism. She has formed the only center on Long Island that carries out these advanced imaging techniques, and her singular work on the human brain has been continuously recognized to be at the forefront of medical research. Additionally, Dr. Ashtari has authored and coauthored more than 87 papers and 300 abstracts. Her study concerning schizophrenia, ADHD, and autism were covered by the international press and featured in numerous news media outlets. Her recent research focuses on using diffusion tensor imaging (DTI), a technique that tracks the movement of water molecules in the brain. Using this technique, Dr. Ashtari and her team found significant decrease of gray matter in the right amyg- 
dale region of the brain that correlated with severity of social impairment in autistic male children between the ages of 8 and 15. If this theory is proven, then maybe children with autism can be recognized even earlier and benefit from early intervention. Many of her works have been presented to scientific meetings all over the world, including her own county of birth, Iran.

When asked what advice she has for her younger and upcoming colleagues Dr. Ashtari provided the following words of wisdom:

"It is essential to always be true to yourself and to always believe in your potential and your abilities despite all the obstacles that might be in your way. I also have found that in my life, it has been equally important to have faith and always keep God on my side. In addition, I always keep as a rule of thumb that when something bitter happens in your life, it will always make you stronger and more determined and often turns out to be a blessing in disguise.

"As a young girl in Tehran, I was the only one of my sisters to complete high school and continue my education, despite continuously being discouraged from doing so. Though we have entered an age of unforeseen progress in women's rights and their professional status in our society, it remains much more difficult for women than men to attain success. A woman must work harder to prove herself, withstand more opposition and discrimination from her colleagues and peers, and juggle more responsibili- ties such as raising children and maintaining a home. "In addition, whether involved in research, medicine, or any other discipline, I have always maintained that integrity and honesty are the most valuable tools you can possess. Especially as a researcher, it is of utmost importance to be honest with your data. I have always advised my research assistants: do not try to make the data fulfill your expectations, try to see what it is telling you and work with your results. The mark of a true scientist is to not work for the sake of ambition and recognition but to strive for the pursuit of truth and knowledge."

Dr. Ashtari is married to Ali Aravand. a civil engineer, and they are blessed with two children. Her daughter, Pouneh, is a New York University graduate, fluent in Farsi and Arabic and is a Fulbright scholar currently in Syria. Her son, Puya, is a firstyear violin performance student at the Manhattan School of Music.

\section{Profile submitted by}

Faroque Ahmad Khan, MB, MACP

Associate Editor, JIMA

Director Research and Publications

King Fahad Medical City

Riyadh, Saudi Arabia

Professor of Medicine

SUNY

Stony Brook, New York 